\title{
Determinant factors of under-five mortality in Southern Nations, Nationalities and People's region (SNNPR), Ethiopia
}

\author{
Gizachew Gobebo (D)
}

\begin{abstract}
Background: Child mortality is a key indicator of the performance of the health system of a nation. Impressive progress in the reduction of under-five mortality has been made in Ethiopia. However, still there are some regions where the under-five mortality rates are high. Southern Nations, Nationalities, and Peoples' Region (SNNPR) is among those regions in Ethiopia with high under-five mortality rates. This study aimed to identify the determinant factors of under-five mortality in SNNPR.
\end{abstract}

Methods: Data used for the study were drawn from the 2016 EDHS. A total of 1277 under-five children were included in the study. A multivariable logistic regression model was fitted to identify determinant factors associated with under-five mortality.

Results: Children with second or third birth order $(\mathrm{OR}=1.316,95 \% \mathrm{Cl}:(1.097,2.343))$, fourth or fifth birth order $(\mathrm{OR}=1.934,95 \% \mathrm{Cl}:(1.678,3.822))$, sixth or above birth order $(\mathrm{OR}=3.980,95 \% \mathrm{Cl}:(2.352,6.734))$ were significantly associated with increased risk of under-five mortality as compared to those with first birth order. Increased risk of under-five mortality was also significantly associated with a family size of five or more (OR $=3.397,95 \% \mathrm{Cl}$ : (1.702, 6.782)) as compared to the family size of less than five; smaller size at birth $(\mathrm{OR}=1.714,95 \% \mathrm{Cl}:(1.120,2.623))$ as compared to larger size at birth; multiple births $(\mathrm{OR}=1.472,95 \% \mathrm{Cl}:(1.289,2.746))$ as compared to singletons. On the other hand, female children $(\mathrm{OR}=0.552,95 \% \mathrm{Cl}:(0.327,0.932))$, children born at health institutions $(\mathrm{OR}=0.449$, $95 \% \mathrm{Cl}:(0.228,0.681))$ and children who were breastfed $(\mathrm{OR}=0.657,95 \% \mathrm{Cl}:(0.393,0.864))$ were significantly associated with decreased risk of under-five mortality as compared to male children, those born at home and those who were not breastfed respectively.

Conclusions: Sex of a child, birth order, size of a child at birth, place of delivery, birth type, breastfeeding status, and family size were significant factors associated with under-five mortality in SNNPR, Ethiopia. Thus, planning and implementing relevant strategies that focus on those identified determinant factors of under-five mortality is required for the improvement of child survival in SNNPR, Ethiopia.

Keywords: Under-five mortality, Determinant factors, SNNPR, Ethiopia

\section{Correspondence: gizmake@gmail.com}

Department of Statistics, College of Natural and Computational Sciences,

Ambo University, Ambo, Ethiopia

C C The Author(s). 2021 Open Access This article is licensed under a Creative Commons Attribution 4.0 International License, which permits use, sharing, adaptation, distribution and reproduction in any medium or format, as long as you give appropriate credit to the original author(s) and the source, provide a link to the Creative Commons licence, and indicate if changes were made. The images or other third party material in this article are included in the article's Creative Commons licence, unless indicated otherwise in a credit line to the material. If material is not included in the article's Creative Commons licence and your intended use is not permitted by statutory regulation or exceeds the permitted use, you will need to obtain permission directly from the copyright holder. To view a copy of this licence, visit http://creativecommons.org/licenses/by/4.0/ The Creative Commons Public Domain Dedication waiver (http://creativecommons.org/publicdomain/zero/1.0/) applies to the data made available in this article, unless otherwise stated in a credit line to the data. 


\section{Background}

Child mortality is a key indicator of the performance of the health system of a nation [1] Remarkable progress in the reduction of mortality among children including children under the age of five has been made globally. In 1990, an estimated 12.6 million deaths occurred among under the age five children and it declined to 5.3 million in 2018. Of the deaths occurred among under the age of five in 2018, 2.5 million (47\%) deaths occurred in the first month of life, 1.5 million (29\%) deaths occurred at age 1-11 months, and 1.3 million (25\%) deaths occurred at age 1-4 years. Sub-Saharan Africa accounts roughly half of all the deaths occurred among under-five children worldwide in 2018. The global under-five mortality rate has dropped by 59\%, from 93 deaths per 1000 live births in 1990 to 39 deaths per 1000 live births in 2018 . This is equivalent to 1 in 11 children dying before reaching age five in 1990, compared to 1 in 26 in 2018 [2].

There are widespread regional and income disparities in children's chances of survival with the WHO African region carrying the highest burden of under-five mortality in the world. Sub-Saharan Africa continues to be the region with the highest risk of dying before the age five in the world with 78 deaths per 1000 live births in 2018 . This means that 1 child in 13 dying his or her before their fifth birthday, which is 16 times higher than the average ratio of 1 child in 199 in high-income countries and 20 times higher than in the region of Australia and New Zealand [2].

In Ethiopia, according to the recent Ethiopian Demographic and Health Survey (2016 EDHS) report, the under-five mortality rate was 67 deaths per 1000 live births, which means 1 in 15 children in Ethiopia dies before reaching age five. The under-five mortality declined from 166 deaths per 1000 live births in 2000 to 67 deaths per 1000 live births in 2016 in the country, which represents a $60 \%$ decrease in under-five mortality over a period of 16 years [3].

Though Ethiopia made an improvement in reduction of under-five mortality in the past two decades, still it is high and therefore more efforts need to be made and appropriate interventions also need to be implemented to meet the Sustainable Development Goals (SDGs) that targeted to reduce under-five mortality rate to at least as low as 25 deaths per 1000 live births by 2030 .

In Ethiopia, the under-five mortality rate varies among the geographical regions [4-7]. Southern Nations Nationalities and People's Region is one of the geographical regions of Ethiopia with high under-five mortality rates $[3,4]$. The 2016 EDHS reported that in SNNPR underfive mortality rate was 88 deaths per 1000 live births [3].

Previously conducted studies showed that under-five mortality is determined by various factors including sex of child [8-11], birth order $[8,11-14]$ size of child at birth $[5,11,13,15]$ breastfeeding status $[11,12,14-17]$ preceding birth interval $[11-13,16,17]$ type of birth [11, $12,15-18]$, place of delivery $[8,11]$. Studies also showed that under-five mortality is determined by mother's age [11] mother age at first birth $[4,5,10-12,15]$ mother's education $[4,5,8,10,11,15]$, sex of the household head [9], household socioeconomic status $[4,16,17,19]$ contraceptive methods use $[13,15]$, family size $[10,12$, $13,16,17]$, types of place of living $[11,13]$, source of drinking water and toilet facility $[9,12,16,17]$, religion, marital status and employment status of mother $[4,11]$.

To my knowledge, there is no study that has been done at regional level in SNNPR on determinant factors of Under-five mortality. Identifying the determinant factors that are associated with under-five mortality is important to inform policy makers to provide relevant alternative interventions or strengthen the existing interventions so as to reduce under-five mortality to the level it is expected. Thus, this study aimed to identify determinant factors associated with under-five mortality in SNNPR, Ethiopia.

\section{Methods}

Data source and study design

The data used for this study were extracted from national cross-sectional demographic and health survey, 2016 EDHS (Ethiopian demographic and health survey) which was conducted from January 18 to June 27, 2016. The 2016 EDHS was designed to provide estimates for the health and demographic variables of interest for Ethiopia as a whole, for urban and rural areas separately, and for each of the nine regions and the two administrative cities of Ethiopia. The 2016 EDHS sample was selected in two stages. In the first stage, a total of 645 enumeration areas were selected with probability proportional to enumeration area size. In the second stage, 28 households per cluster were selected with an equal probability systematic selection from the household list. Among the 2016 EDHS data, the kids data (data on children born in the 5 years prior to the interview) corresponding to SNNPR were used for final analysis.

\section{Study area}

The Southern Nations, Nationalities, and People's Region (SNNPR) is one of the administrative regions of Ethiopia. The region has estimated population of 19.17 million in 2017.

Table 1 Prevalence of under-five mortality in SNNPR, Ethiopia

\begin{tabular}{llll}
\hline & & Counts & Percent \\
\hline Child status & Died & 71 & 5.6 \\
& Alive & 1206 & 94.4 \\
& Total & 1277 & 100 \\
\hline
\end{tabular}


Table 2 Bivariate analysis of under-five mortality by background characteristics of mothers and children

\section{Place of residence}

Characteristics/Variables

Rural

Urban

Mother's age at first birth

$$
\begin{aligned}
& \text { Less than } 20 \\
& \text { 20-29 }
\end{aligned}
$$$$
30 \text { or older }
$$

Total counts

U5M (Counts)

69

2

95

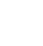

723

451

103

Mother's current age

$\begin{array}{ll}15-19 & 29 \\ 20-24 & 203 \\ 25-29 & 418 \\ 30-34 & 301 \\ 35 \text { or older } & 326\end{array}$

Sex of child

Male

Birth order

First

Second or Third

Fourth or Fifth

Sixth or above

Mother's education level

No education
Primary
Secondary
Higher

\section{Contraceptive methods}

No

Yes

Household wealth index

$\begin{array}{ll}\text { Poorest } & 234 \\ \text { Poorer } & 306 \\ \text { Middle } & 303 \\ \text { Richer } & 287 \\ \text { Richest } & 147\end{array}$

\section{Family size}

Less than 5

5 or more

930

Size of child at birth

$\begin{array}{ll}\text { Larger } & 439 \\ \text { Average } & 567 \\ \text { Smaller } & 271\end{array}$

Sex of household

23

10

23

45

\section{U5M (Percent)}

$P$-value

5.8

2.1

5.3

0.158

5.1

9.7

0.545

6.9

3.9

4.8

6.0

7.1

6.8

0.021

4.2

5.2

0.016

4.6

6.1

6.3

6.2

0.420

4.9

5.0

0 
Table 2 Bivariate analysis of under-five mortality by background characteristics of mothers and children (Continued)

\begin{tabular}{|c|c|c|c|c|}
\hline Characteristics/Variables & Total counts & U5M (Counts) & U5M (Percent) & $P$-value \\
\hline Female & 170 & 13 & 7.6 & \\
\hline \multicolumn{5}{|l|}{ Place of delivery } \\
\hline Home & 906 & 58 & 6.4 & \multirow[t]{2}{*}{0.005} \\
\hline Health Institutions & 371 & 13 & 3.5 & \\
\hline \multicolumn{5}{|l|}{ Birth type } \\
\hline Single & 1251 & 65 & 5.2 & \multirow[t]{2}{*}{0.000} \\
\hline Multiple & 26 & 6 & 23.1 & \\
\hline \multicolumn{5}{|l|}{ Breastfeeding status } \\
\hline No & 415 & 47 & 11.3 & \multirow[t]{2}{*}{0.000} \\
\hline Yes & 862 & 24 & 2.8 & \\
\hline \multicolumn{5}{|l|}{ Mother's work status } \\
\hline Not working & 795 & 33 & 4.2 & \multirow[t]{2}{*}{0.030} \\
\hline Working & 482 & 38 & 7.9 & \\
\hline \multicolumn{5}{|l|}{ Toilet Facility } \\
\hline No facility & 304 & 31 & 10.2 & \multirow[t]{2}{*}{0.240} \\
\hline Have facility & 973 & 40 & 4.1 & \\
\hline \multicolumn{5}{|l|}{ Source of drinking water } \\
\hline Unprotected & 580 & 37 & 6.4 & \multirow[t]{2}{*}{0.500} \\
\hline Protected & 697 & 34 & 4.9 & \\
\hline
\end{tabular}

\section{Variables of the study}

\section{Dependent variable}

The dependent variable is death of under-five children.

\section{Predictor variables}

Based on previously conducted studies, various demographic, socio-economic, biological, and environmental factors were included as predictor variables: mother's age at first birth, mother's current age, mother's educational level, sex of household, mother's work status, contraceptive methods, household wealth index, family size, sex of child, birth order, birth type, size of child at birth, breastfeeding status, place of residence, place of delivery, toilet facility, and source of drinking water.

\section{Data analysis}

Data analysis was done using STATA version 14.

\section{Statistical analysis}

The background characteristics of the sample were summarized using descriptive statistics like frequencies and percentages. Bivariate analysis using Pearson chi-square test was used to test the association between under-five mortality and the predictor variables. The multivariable logistic regression model was applied to identify the determinant factors of under-five children mortality.

\section{Results}

\section{Descriptive statistics}

In this study, a total of 1277 under-five children were included. Of the total under-five children, $71(5.6 \%)$ of them were reported dead before the age of 5 years (Table 1).

\section{Result of bivariate analysis}

As it shown in Table 2, the higher percentage (97.2\%) of under-five mortality was observed among rural children than the urban children (2.8\%). It was also higher among male children (6.8\%) than female children (4.2\%). Similarly, it was higher among children of multiple births (23.1\%) than children of single birth (5.2\%). Regarding birth order, it was highest among children whose birth order was sixth or above (6.3\%) while it was lowest among children whose birth order was second or third (4.6\%). It was also highest among children whose size at birth was smaller (8.5\%) and lowest among children whose size at birth was average $(3.5 \%)$.

The under-five mortality decreases with increased level of education of mothers. It was highest among children whose mothers were not educated (6.2\%) while no under-five mortality was observed among children whose mothers attended higher than secondary school. Similarly, it was highest among the children whose mothers aged 30 or older at first birth (9.3\%) and lowest 
among the children whose mothers aged 20 to 29 at first birth (5.1\%).

The under-five mortality varied with household wealth index, mother's work status, family size and sex of head of household. It was highest among households with wealth indices poorer $(6.9 \%)$ and lowest among households with wealth indices richest (2.0\%). Similarly, it was higher among the children whose mothers were working $(7.9 \%)$ than those whose mothers were not working (4.2\%). Regarding family size, the under-five mortality was higher among the children born in families with family size of less than (8.1\%) than those born in families with family size of five or more (4.6\%). Similarly, it was higher among children who were from households headed by females (7.6\%) than among those who were from households headed by males (5.2\%).

Under-five mortality also varied with contraceptive methods, place of delivery, breastfeeding and source of drinking water. It was higher among children whose mothers did not use any of the contraceptive methods (6.5\%) than those whose mothers used any of the contraceptive methods (4.2\%). It was higher among children born at home (6.4\%) than those born at health in institutions (3.5\%). Similarly, it was higher for the children who were not breastfed $(11.3 \%)$ than those who were breastfed $(2.8 \%)$. There was also higher (6.4\%) under-five mortality among children who used unprotected source of drinking water than those who used protected source of drinking water (4.9\%).

The multivariable logistic regression analysis (Table 3) revealed that sex of a child, birth order, size of a child at birth, place of delivery, birth type, breastfeeding status, and family size were statistically significant determinant factors of under-five children mortality at $5 \%$ level of significance. The odds of under-five children death among females was 0.552 (OR $=0.552$, 95\% CI: (0.327, 0.932)) times lower than males. Children with birth order of second or third (OR $=1.316,95 \% \mathrm{CI}$ : (1.097, $2.343))$, children with birth order of fourth or fifth $(\mathrm{OR}=$ 1.934, 95\% CI: $(1.678,3.822))$ and children with birth order of sixth or above (OR $=3.980,95 \%$ CI: $(2.352$, 6.734)) were associated with increased odds of underfive death compared to those with birth order of first. Similarly, children from families with five or more members had higher odds $(\mathrm{OR}=3.397,95 \% \mathrm{CI}$ : (1.702, 6.782)) of under-five death compared to those from families with less than five members.

Children with smaller size at birth $(\mathrm{OR}=1.714,95 \%$ CI: $(1.120,2.623))$ were associated with increased odds of under-five death compared to those with larger size at birth. Similarly, children of multiple births $(\mathrm{OR}=1.472$, 95\% CI: $(1.289,2.746))$ were associated with increased odds of under-five death compared to children of single birth.

Children born at health institutions had lower odds $(\mathrm{OR}=0.449,95 \% \mathrm{CI}:(0.228,0.681))$ of under-five death
Table 3 Result of multivariable logistic regression analysis

\begin{tabular}{|c|c|c|c|c|}
\hline \multirow{2}{*}{$\begin{array}{l}\text { Variables } \\
\text { Sex of child (Ref: Male }\end{array}$} & \multirow[t]{2}{*}{ OR } & \multirow[t]{2}{*}{$p>z$} & \multicolumn{2}{|c|}{$95 \% \mathrm{Cl}$ of $\mathrm{OR}$} \\
\hline & & & & \\
\hline Female & 0.552 & $0.026^{\mathrm{a}}$ & 0.327 & 0.932 \\
\hline \multicolumn{5}{|c|}{ Birth order (Ref: First) } \\
\hline Second or Third & 1.316 & $0.039^{\mathrm{a}}$ & 1.097 & 2.343 \\
\hline Fourth or Fifth & 1.934 & $0.018^{\mathrm{a}}$ & 1.678 & 3.822 \\
\hline Sixth or above & 3.980 & $0.027^{\mathrm{a}}$ & 2.352 & 6.734 \\
\hline \multicolumn{5}{|c|}{ Household wealth index (Ref: Poorest) } \\
\hline Poorer & 1.125 & 0.757 & 0.532 & 2.379 \\
\hline Middle & 0.825 & 0.639 & 0.371 & 1.839 \\
\hline Richer & 0.967 & 0.934 & 0.440 & 2.128 \\
\hline Richest & 0.330 & 0.100 & 0.088 & 1.235 \\
\hline \multicolumn{5}{|c|}{ Family size (Ref: < 5) } \\
\hline 5 or more & 3.397 & $0.001^{a}$ & 1.702 & 6.782 \\
\hline \multicolumn{5}{|c|}{ Place of delivery (Ref: Home) } \\
\hline Health Institutions & 0.449 & $0.011^{\mathrm{a}}$ & 0.228 & 0.681 \\
\hline \multicolumn{5}{|c|}{ Birth type (Ref: Single) } \\
\hline Multiple & 1.472 & $0.002^{\mathrm{a}}$ & 1.289 & 2.746 \\
\hline \multicolumn{5}{|c|}{ Size of child at birth (Ref: Larger) } \\
\hline Average & 1.324 & 0.094 & 0.700 & 2.504 \\
\hline Smaller & 1.714 & $0.024^{\mathrm{a}}$ & 1.120 & 2.623 \\
\hline \multicolumn{5}{|c|}{ Sex of household head (Ref: Male) } \\
\hline Female & 0.555 & 0.160 & 0.390 & 1.879 \\
\hline \multicolumn{5}{|c|}{ Breastfeeding status (Ref: No) } \\
\hline Yes & 0.657 & $<0.0001^{a}$ & 0.393 & 0.864 \\
\hline
\end{tabular}

\section{Mother's work status (Ref: Not working)}

$\begin{array}{lllll}\text { Working } & 1.448 & 0.158 & 0.866 & 2.0419\end{array}$

Ref Reference category, $\mathrm{Cl}$ confidence Interval, OR Odds Ratio, ${ }^{\text {a }}$ Significant at $5 \%$ level of significance.

compared to those born at home. Similarly, children who were breastfed, for any period, had lower odds $(\mathrm{OR}=0.657,95 \% \mathrm{CI}:(0.393,0.864))$ of under-five death compared those who were not breastfed.

\section{Goodness-of-fit}

The goodness of fit of the model was examined by using Hosmer-Lemeshow goodness-of-fit test.

Hypothesis test:

$\mathrm{H}_{0}$ : The model is a good fit Versus.

$\mathrm{H}_{1}$ : The model is not a good fit.

Since the $p$-value $=0.414>0.05$, we do not reject the null hypothesis and we conclude that the model is a good fit (Table 4).

Table 4 Hosmer-Lemshow goodness-of-fit test

\begin{tabular}{lc}
\hline Hosmer-Lemeshow test & $\boldsymbol{p}$-value \\
\hline 8.204 & 0.414 \\
\hline
\end{tabular}


Table 5 Background characteristics of mothers and children in SNNPR Region, Ethiopia

Characteristics/Variables

Place of residence

Rural

Urban

Mother's age at first birth

Less than 20

20-29

30 or older

Mother's current age

$$
\begin{aligned}
& 15-19 \\
& 20-24 \\
& 25-29 \\
& 30-34 \\
& 35 \text { or older }
\end{aligned}
$$

Sex of child

$$
\text { Male }
$$

Birth order

First

Second or Third

Fourth or Fifth

Sixth or above

Mother's education level

No education
Primary
Secondary
Higher

Contraceptive methods

No

Yes

Household wealth index

$\begin{array}{ll}\text { Poorest } & 23 \\ \text { Poorer } & 306 \\ \text { Middle } & 303 \\ \text { Richer } & 287 \\ \text { Richest } & 147\end{array}$

\section{Family size}

Less than 5

5 or more

Size of child at birth

$$
\begin{aligned}
& \text { Larger } \\
& \text { Average } \\
& \text { Smaller }
\end{aligned}
$$

Sex of household 
Table 5 Background characteristics of mothers and children in SNNPR Region, Ethiopia (Continued)

\begin{tabular}{|c|c|c|}
\hline Characteristics/Variables & Counts & Percent \\
\hline Female & 170 & 13.3 \\
\hline \multicolumn{3}{|l|}{ Place of delivery } \\
\hline Home & 906 & 70.9 \\
\hline Health Institutions & 371 & 29.1 \\
\hline \multicolumn{3}{|l|}{ Birth type } \\
\hline Single & 1251 & 98.0 \\
\hline Multiple & 26 & 2.0 \\
\hline \multicolumn{3}{|l|}{ Breastfeeding status } \\
\hline No & 415 & 32.5 \\
\hline Yes & 862 & 67.5 \\
\hline \multicolumn{3}{|l|}{ Mother's work status } \\
\hline Not working & 795 & 62.3 \\
\hline Working & 482 & 37.7 \\
\hline \multicolumn{3}{|l|}{ Toilet Facility } \\
\hline No facility & 304 & 23.8 \\
\hline Have facility & 973 & 76.2 \\
\hline \multicolumn{3}{|l|}{ Source of drinking water } \\
\hline Unprotected & 580 & 45.4 \\
\hline Protected & 697 & 54.6 \\
\hline
\end{tabular}

\section{Discussion}

Of the total of 1277 under-five children included in this study, 71(5.6\%) of them were reported dead before the age of 5 years. Majority $(92.6 \%)$ of the children were living in rural areas while the remaining $7.4 \%$ of them were living in urban areas. $51.4 \%$ of the children were males and the remaining $48.6 \%$ of them were females. Majority (98\%) of the children's birth type was single and only $2 \%$ of the children's birth type was multiple. About twothird $(67.5 \%)$ of the children were breastfed while the remaining $32.5 \%$ were not. More than two-third $(70.9 \%)$ of the children were born at home and only $29.1 \%$ of them were born at health institutions. The majority $(30.5 \%)$ of the children had birth order of second or third, about $24 \%$ of them had birth order of fourth or fifth, $18 \%$ of them had birth order of first and the remaining $27.3 \%$ of them had birth order of sixth or above. Majority (44.4\%) of the children had average size, about $34.4 \%$ of them had size of above average while the remaining $21.2 \%$ of them had size of below average at birth. More than two-third (72.8\%) of the children were from families with family size of five or more while the remaining $27.2 \%$ of them were from families with family size of less than five (Table 5).

The result of the multivariate logistic regression analysis revealed that male children were at higher risk of under-five mortality compared to female children. This result is consistent with the result of previous studies [9,
11, 20-22]. The possible explanation for this might be that male children are biologically weaker than their female counterparts due to a fundamental genetic advantage.

Children of higher birth order had higher risk of under-five mortality compared to those children of lower birth order. This is consistent with the previous study $[13,16]$. The reason for this might be that as birth order increases care given to child by mother decreases because of having more children.

It was found that children from larger family size were more likely to die before the age of 5 years compared to those children from smaller family size. This is consistent with findings of the previously done studies $[13,17]$. This might be due to that as family size increases, the share of foods and other limited sources required for the child survival decreases.

Children born at home were more likely to die before the age of 5 years compared to those born at health institutions. This result agrees with the finding of the previous study $[8,16]$. This might be due to the fact that children born at home are more susceptible to infections.

It was also found that children who were breastfed were associated with lower odds of under-five mortality compared to those who were not breastfed. This result is consistent with the results of previous studies [10, 14, 17]. The possible explanation for this might be that 
breast milk helps build and support baby's immune system that defends body against invaders, such as viruses and bacteria.

It was also found that children of multiple births were at higher risk of under-five mortality compared to singletons. This is consistent with findings of the previously studies $[5,17,18,20]$. The possible explanation for this might be that foods and other limited resources and care given to child by mother are shared.

Children with smaller size at birth were found to have higher odds of under-five mortality than those with larger size at birth. This result agrees with the result of previous study [16].

\section{Conclusions}

The study aimed at identifying the determinants of under-five mortality in Southern Nations Nationalities and People Region, Ethiopia. A total of 1277 under- five children were included in the study. It was found that sex of a child, birth order, size of a child at birth, place of delivery, birth type, breastfeeding status, and family size were significant determinants of under-five mortality in SNNPR, Ethiopia.

\section{Limitations of the study}

One of the limitations of this study was that factors such as preceding birth interval, number of antenatal care visits during pregnancy, which are supposed to be associated with under-five mortality were not included in the study because of high missing values in the data. The other limitation was that mothers might forget events that occurred in the past 5 years preceding the survey which could have introduced recall bias.

\section{Abbreviations}

CSA: Central Statistics Agency; DHS: Demographic and Health Survey; EDHS: Ethiopian Demographic and Health Survey; SDGs: Sustainable Development Goals; OR: Odds Ratio; SNNPR: Southern Nations, Nationalities, and Peoples' Region; U5M: Under-five mortality; WHO: World Health Organization

\section{Acknowledgments}

The author is very grateful to Central Statistical Agency of Ethiopia for providing the data.

\section{Author's contributions}

The author, GGM, designed the study, analysed data, interpreted the results, prepared and finalized the manuscript. The author(s) read and approved the final manuscript.

\section{Funding}

This study was not funded.

\section{Availability of data and materials}

The data used for this study for final analysis are available from the author upon reasonable request.

\section{Declarations}

Ethics approval and consent to participate

This study was based on the publicly available secondary data which ! downloaded from the DHS website (http:// dhsprogram.com) after getting permission. Because of that, Ethics approval and consent to participant were not necessary.

\section{Consent for publication}

Not applicable.

\section{Competing interests}

The author declares that he has no competing interests.

Received: 8 April 2021 Accepted: 19 July 2021

Published online: 30 October 2021

\section{References}

1. Hill K, You D, Inoue M, Oestergaard MZ. Child mortality estimation: accelerated progress in reducing global child mortality, 1990-2010. PLoS Med. 2012;9(8):e1001303. https://doi.org/10.1371/journal.pmed.1001303.

2. United Nations Inter-agency Group for Child Mortality Estimation (UN IGME) Levels \& Trends in Child Mortality: Report 2019, Estimates developed by the United Nations Inter-agency Group for Child Mortality Estimation. New York: United Nations Children's Fund; 2019. (http://www.childmortality.org)

3. Central Statistical Agency (CSA) [Ethiopia] and ICF. Ethiopia Demographic and Health Survey 2016. Addis Ababa: CSA and ICF; 2016.

4. Getiye TI. Identification of risk factors and regional differentials in under five mortality in Ethiopia using multilevel count model. Addis Ababa: PhD diss., M. Sc. Thesis, Addis Ababa University; 2011.

5. Bedane AS, Asena TF, Shamenna AT, Abshoko AD. Variations in under-five child mortality among regional states of Ethiopia: a multi-level modelling approach. Curr J Appl Sci Technol. 2016;17:1-6.

6. Ayele DG, Zewotir TT. Comparison of under-five mortality for 2000, 2005 and 2011 surveys in Ethiopia. BMC Public Health. 2016;16(1):930. https://doi. org/10.1186/s12889-016-3601-0.

7. CSA Central Statistics Agency of Ethiopia and ORC Macro. Ethiopia Demographic and Health Survey 2016, vol. 2016. Calverton.

8. Buwembo P. Factors associated with under-5 mortality in South Africa: trends 1997-2002: PhD diss., University of Pretoria; 2010.

9. Nasejje J. Application of survival analysis methods to study under-five child mortality in Uganda: PhD diss., University of KwaZulu-Natal; 2013.

10. Bedada D. Determinant of under-five child mortality in Ethiopia. Am J Theor Appl Stat. 2017;6(4):198-204. https://doi.org/10.11648/j.ajtas.20170604.15.

11. Yaya S, Bishwajit G, Okonofua F, Uthman OA. Under five mortality patterns and associated maternal risk factors in sub-Saharan Africa: a multi-country analysis. PLoS One. 2018 Oct 25;13(10):e0205977. https://doi.org/10.1371/ journal.pone.0205977.

12. Bereka SG, Habtewold FG, Nebi TD. Under-five mortality of children and its determinants in Ethiopian Somali regional state, Eastern Ethiopia. Health Sci J. 2017:11(3):1

13. Kayode GA, Adekanmbi VT, Uthman OA. Risk factors and a predictive model for under-five mortality in Nigeria: evidence from Nigeria demographic and health survey. BMC Pregnancy Childbirth. 2012;12(1):10. https://doi.org/10.11 86/1471-2393-12-10.

14. Mani K, Dwivedi SN, Pandey RM. Determinants of under-five mortality in rural empowered action group states in India: an application of cox frailty model. Int J MCH AIDS. 2012;1(1):60-72. https://doi.org/10.21106/ijma.9.

15. Kanmiki EW, Bawah AA, Agorinya I, Achana FS, Awoonor-Williams JK, Oduro $A R$, et al. Socio-economic and demographic determinants of under-five mortality in rural northern Ghana. BMC Int Health Hum Rights. 2014;14(1):24. https://doi.org/10.1186/1472-698X-14-24.

16. Woldeamanuel BT. Socioeconomic, demographic, and environmental determinants of under-5 mortality in Ethiopia: evidence from Ethiopian demographic and health survey, 2016. Child Dev Res. 2019;2019:1-15. https://doi.org/10.1155/2019/1073782

17. Gebretsadik S, Gabreyohannes E. Determinants of under-five mortality in high mortality regions of Ethiopia: an analysis of the 2011 Ethiopia Demographic and Health Survey data. International Journal of Population Research. 2016;2016:1-7. https://doi.org/10.1155/2016/1602761. 
18. Dwomoh D, Amuasi S, Agyabeng K, Incoom G, Alhassan Y, Yawson AE. Understanding the determinants of infant and under-five mortality rates: a multivariate decomposition analysis of demographic and health surveys in Ghana, 2003, 2008 and 2014. BMJ Glob Health. 2019 Jul 1:4(4):e001658. https://doi.org/10.1136/bmjgh-2019-001658.

19. Ettarh $\mathrm{R}$, James $\mathrm{K}$. Determinants of under-five mortality in rural and urban Kenya; 2012.

20. Aheto JM. Predictive model and determinants of under-five child mortality: evidence from the 2014 Ghana demographic and health survey. BMC Public Health. 2019;19(1):64. https://doi.org/10.1186/s12889-019-6390-4.

21. Adebowale SA, Morakinyo OM, Ana GR. Housing materials as predictors of under-five mortality in Nigeria: evidence from 2013 demographic and health survey. BMC Pediatr. 2017;17(1):30. https://doi.org/10.1186/s12887-01 6-0742-3.

22. Getachew $Y$, Bekele $S$. Survival analysis of under-five mortality of children and its associated risk factors in Ethiopia. J Biosens Bioelectron. 2016;7(213):2.

\section{Publisher's Note}

Springer Nature remains neutral with regard to jurisdictional claims in published maps and institutional affiliations.

Ready to submit your research? Choose BMC and benefit from:

- fast, convenient online submission

- thorough peer review by experienced researchers in your field

- rapid publication on acceptance

- support for research data, including large and complex data types

- gold Open Access which fosters wider collaboration and increased citations

- maximum visibility for your research: over $100 \mathrm{M}$ website views per year

At BMC, research is always in progress.

Learn more biomedcentral.com/submissions 